\title{
Importance of Collection Overhangs on the Efficacy of Exclusion Fences for Managing Cabbage Flies (Diptera: Anthomyiidae)
}

\author{
MICHAEL K. BOMFORD, ROBERT S. VERNON, AND PEETER PÄTS
}

Pacific Agri-Food Research Centre, Agriculture and Agri-Food Canada, Box 1000, Agassiz, BC, Canada V0M 1A0

Environ. Entomol. 29(4): 795-799 (2000)

\begin{abstract}
Fine nylon mesh fences (135 cm high) with varying lengths of downward-sloping collection overhangs were evaluated for efficacy in excluding the female cabbage flies Delia radicum (L.) from plots of radish, Raphanus sativus (L.). During three trials conducted in 1994 and 1995, fences without overhangs, fences with 12.5 -cm overhangs, or fences with 50 -cm overhangs were tested against fences with standard 25 -cm overhangs and unfenced control plots. In fenced plots with standard 25-cm overhangs, the mean number of $D$. radicum females caught on yellow sticky traps placed within plots was $85 \%$ less than those caught in corresponding control plots. The mean numbers of $D$. radicum females caught in fenced enclosures with no overhangs, 12.5 -cm overhangs, or 50 -cm overhangs, were 61,67 , and $94 \%$ less than those caught in corresponding control plots, respectively. The mean proportion of radishes damaged by $D$. radicum larvae inside enclosures with $25-\mathrm{cm}$ overhangs was $62 \%$ less than in corresponding control plots. The mean proportions of radishes damaged inside fences with no overhangs, 12.5 -cm overhangs, or 50 -cm overhangs were 33,59 , and $81 \%$ less than those caught in corresponding control plots, respectively. Results are discussed in terms of defining an appropriate fence design for commercial use.
\end{abstract}

KEY WORDS Delia radicum, physical control, radish

Delia radicum (L.) is a chronic and often limiting pest in the commercial production of cruciferous vegetable crops in the northern hemisphere. Damage is usually so predictable that most growers routinely apply soil treatments of granular insecticide or insecticide applied as a drench to adequately protect their crops. Because of the availability of efficacious insecticides diminishing there is an urgent need to develop alternative management strategies for $D$. radicum.

The search for alternatives to insecticides for control of $D$. radicum has focused on a number of cultural and physical control strategies for D. radicum, some of which were used before the advent of modern chemical insecticides. Cultural practices such as crop rotation, field sanitation, removal of alternate hosts, trap cropping, and timing plantings to avoid critical $D$. radicum flight periods all show promise as components of integrated pest management strategies (Finch 1993). Physical control methods have included the use of tar paper or foam rubber collars placed around plant stalks to prevent oviposition (Schoene 1914, Wheatley 1975, Skinner and Finch 1986), and various types of row covers to exclude adult $D$. radicum (Haseli and Conrad 1987, Hough-Goldstein 1987, Millar and Isman 1988).

A new physical control strategy under evaluation for $D$. radicum is the exclusion fence (Vernon and Mackenzie 1998). The fence consists of vertical panels of nylon window screen, with a downward-sloping screen overhang at the top (Fig. 1). The vertical panel intercepts low-flying $D$. radicum moving into the crop at the crop/headland interface, whereas the downward-sloping screen overhang at the top is designed to collect and retard intercepted flies from moving up and over the fence. The fence has significantly reduced the immigration of $D$. radicum females into plantings of rutabaga, Brassica napus napobrassica (L.), resulting in reduced root maggot damage (Vernon and Mackenzie 1998). The height of the vertical screen panel is very important, with $D$. radicum exclusion increasing as fence height increases from 0 to $90 \mathrm{~cm}$ (Vernon and Mackenzie 1998). No work has been done, however, to evaluate the optimal size of the screen collection overhang at the top, or to determine if this component improves exclusion. These questions are important in designing the most costeffective exclusion fence for use in commercial fields.

This article investigates the influence of the length of the screen collection overhang on the efficacy of the exclusion fence in reducing immigration of $D$. radicum females into radish, Raphanus sativus (L.), plantings and the subsequent damage caused by $D$. radicum larval feeding on radishes.

\section{Materials and Methods}

Fence Design. The vertical panels were commercially available, aluminum framed window screens of 1-mm black nylon mesh ( $210 \mathrm{~cm}$ long by $120 \mathrm{~cm}$ high) (Stollco Industries, Port Coquitlam, BC) supported by wooden fence posts $(7.5 \mathrm{~cm}$ by $9 \mathrm{~cm}$ wide by $120 \mathrm{~cm}$ high) (Fig. 1). At the top of each panel, a wooden 


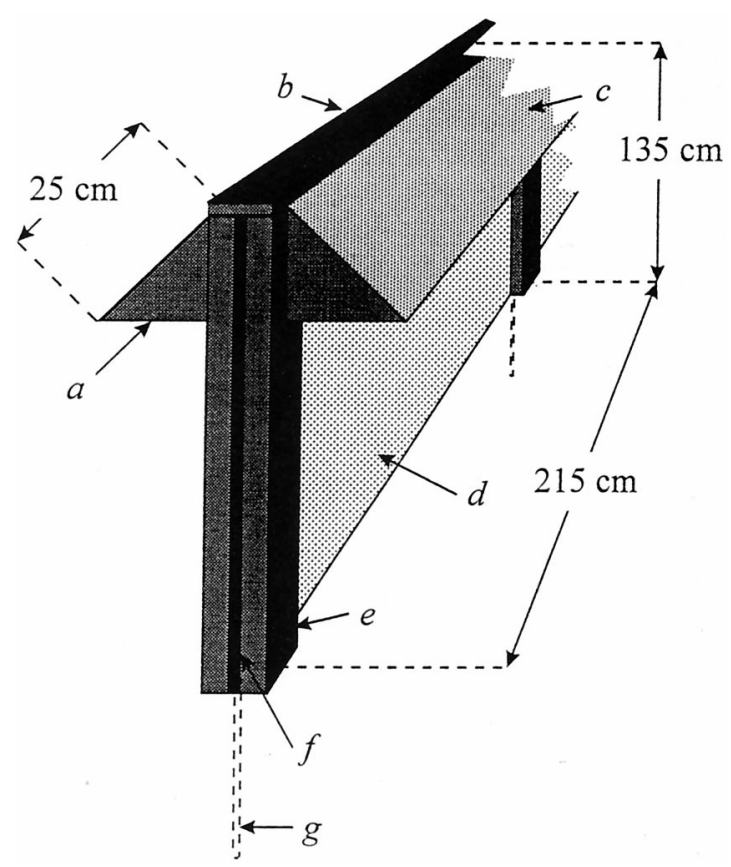

Fig. 1. Design of exclusion fence with 25-cm overhangs. Fence components include (a) overhang support wing (b) wooden fence top, (c) mesh overhang, (d) mesh screen, (e) hollow wooden fencepost, (f) groove in postfor screen, and (g) rebar to anchor post.

fence top ( $2 \mathrm{~cm}$ high by $8 \mathrm{~cm}$ wide by $210 \mathrm{~cm}$ long) rested on the top edge of the aluminum frame. From this wooden top, separate strips of 1-mm mesh nylon screen were attached to form mesh overhangs of specified lengths angled downward at $45^{\circ}$ on both sides of the fence. The $45^{\circ}$ angles of the overhangs were maintained by securing the mesh overhangs to plywood triangles attached to the tops of the fence posts (Fig. 1). All wooden components, including the mesh screens, were painted black.

Experimental Design. The experimental site was a mowed field of mixed grass near Abbotsford, $80 \mathrm{~km}$ east of Vancouver, British Columbia. The trials were arranged in a randomized complete block design with four blocks, $30 \mathrm{~m}$ apart. Each block contained three 7-m square plots, $10 \mathrm{~m}$ apart, covered with black woven landscape fabric (Lumite 994, Division of Synthetic Industries, Norcross, GA) to prevent the growth of alternate weed hosts for D. radicum. The three plots in each block were as follows: (1) an unfenced control plot, (2) a plot enclosed by a fence with a standard overhang $25 \mathrm{~cm}$ in length, and (3) a plot enclosed by a fence with overhang lengths of $0 \mathrm{~cm}$ (trial 1: 13 July to 10 August 1994), $12.5 \mathrm{~cm}$ (trial 2: 12-30 August 1994), or $50 \mathrm{~cm}$ (trial 3: 23 August to 14 September $1995)$. Fences enclosed a 4.3 by $4.3-\mathrm{m}$ square in the center of each treatment plot.

To provide host odor within the enclosures, black plastic flats containing 50 radish seedlings (CV 'Cavalrondo') were established in a screenhouse free of $D$. radicum, and transferred to the plots at the start of each trial. Radish seedlings were 7,15 , and $6 \mathrm{~d}$ old when transferred to the plots in the three trials, respectively. The flats were arranged in three rows of three flats on top of the landscape fabric, and were evenly spaced to fill a 3.5 by $3.5-\mathrm{m}$ square in the center of each plot. Radishes were watered daily from the beginning to the end of each trial.

Insect Trapping. Sticky traps were used to monitor winged insect populations within the plots. Traps were made from sheets of white cardboard (4-ply Railroad Board; Domtar Fine Papers, Toronto, ON, Canada), painted on both sides with yellow, semigloss enamel paint (Yellow 776, Cloverdale Paint and Chemicals, Surrey, BC, Canada), cut into 10 by $14-\mathrm{cm}$ rectangles, and dipped in a commercial insect adhesive (Stiky Stuff, Olson Products, Medina, OH). Traps were attached to wooden stakes, with the bottom edge $(14 \mathrm{~cm}$ long) $15 \mathrm{~cm}$ above the ground. Each plot contained two traps, located $1.5 \mathrm{~m}$ northeast and southwest of the plot center. The traps were replaced at 2- to 6 - $\mathrm{d}$ intervals, and captured Delia spp. were identified by using a dissecting microscope and the diagnostic key of Brooks (1951). To prevent birds from eating insects off the traps in the first trial, Stiky Stuff was applied, every $2 \mathrm{wk}$, to a 60 by $60-\mathrm{cm}$ area of landscape fabric surrounding the base of each stake. In the second and third trials, traps were enclosed in $60 \mathrm{~cm}$ high pyramidshaped black nylon tents (4-cm mesh), which prevented bird damage while allowing the free passage of insects.

Radish Damage. At the end of each trial, three of the nine flats of radishes in each plot were removed to a screenhouse free of $D$. radicum for damage assessments. Flats were taken from the same positions in each plot, with the positions of the flats being selected randomly for each trial. Flats were watered daily in the screenhouse by an overhead irrigation system. After an incubation period of 8-12 d for the first and second trials, and 25-30 d for the third trial, the dead and living radishes were counted in each flat. Surviving radishes were inspected externally and internally for root damage caused by feeding by $D$. radicum larvae.

Statistical Analysis. The trapping data were transformed (square root $x+0.5$ ) to correct for heterogeneity of variance. Data from each trapping session and pooled data for all sessions within each trial were subjected to analysis of variance (ANOVA), and means were separated using the Tukey test (Zar 1998). The number of damaged radishes were expressed as a percentage of the total number of surviving radishes, and the number of dead radishes was expressed as a percentage of the total number of radishes which germinated. These data were transformed by arcsine square root, and analyzed by ANOVA, and the Tukey test. A minimum significance level of $P=0.05$ was maintained for all statistical tests.

\section{Results}

Exclusion of Female D. radicum. When trapping data were pooled at the end of the first two trials, significantly more female D. radicum had been caught 


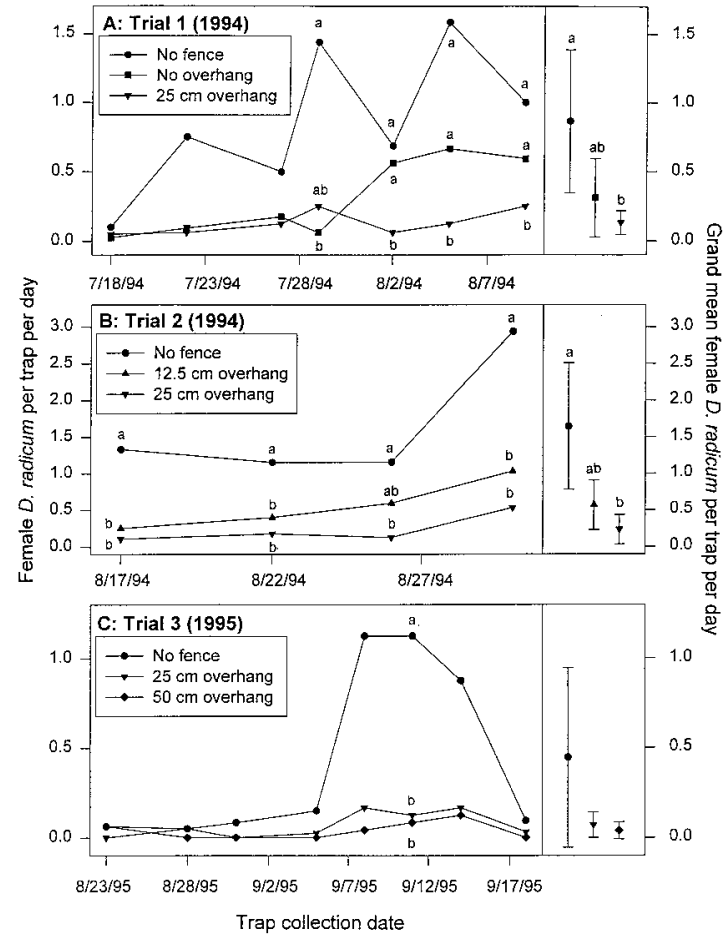

Fig. 2. Mean number of $D$. radicum females caught on yellow sticky traps in unfenced control plots and in plots enclosed by fences containing 25 -cm overhangs, versus plots enclosed by fences with no overhangs (A), with $12.5-\mathrm{cm}$ overhangs (B) or with 50-cm overhangs (C). Means labeled with the same letter on any trapping date are not significantly different at $\alpha=0.05$ (Tukey test). No labels are shown when no significant differences occurred. Error bars denote the standard error of the grand mean for all trapping sessions.

on sticky traps in the control plots than in fenced plots with 25-cm overhangs (Fig. $2 \mathrm{~A}$ and $\mathrm{B}$ ). This trend continued in the third trial, but differences were not significant (Fig. 2C). D. radicum catches fluctuated substantially over the course of each trial, and treatment effects were most pronounced when catches were high.

In the first trial, the grand mean of female D. radicum caught inside fences with no overhangs was not significantly different from that inside fences with 25-cm overhangs (Fig. 2A). When trapping sessions were analyzed individually, however, significantly more females were caught inside fences with no overhangs than inside fences with 25 -cm overhangs in the final three sampling sessions. During these three sampling sessions, numbers of females in the control plots were not significantly different from numbers inside the fences with no overhangs, but were greater than in fences with 25 -cm overhangs.

When trap data were pooled for the second trial, female $D$. radicum catches were not significantly different inside fences with 12.5 -cm overhangs and those with $25-\mathrm{cm}$ overhangs (Fig. 2B). Significantly more females were caught in the control plots than in the fenced plots with 12.5-cm overhangs on three out of four sampling sessions. Catches were always higher in control plots than inside fenced plots with 25 -cm overhangs.

Catches of D. radicum were lowest in the third trial. Catches were equally low in all plots during the first four sampling sessions, but increased in the control plots during the latter sessions (Fig. 2C). Numbers of females caught inside fenced plots with 50 -cm overhangs were not significantly different from numbers caught in fenced plots with 25-cm overhangs. Significant differences between control plots and fenced plots only occurred during one trapping session.

Radish Damage. Feeding by D. radicum larvae was the sole cause of reported damage, and the principal cause of radish mortality. The cause of mortality could not be determined for the most severely decomposed radishes, however, so mortality is reported separately from maggot damage to surviving radishes (Table 1).

In the first trial, the proportion of damaged radishes was significantly higher in the control plots than in fenced plots with 25-cm overhangs (Table 1). Damage in fenced plots with no overhangs was intermediate to damage in the control plots and fenced plots with $25-\mathrm{cm}$ overhangs. Significantly more radishes died in the control plots than in the two fenced treatments.

In the second trial, the proportion of radishes damaged in the control plots was significantly higher than in fenced plots with 12.5- and 25-cm overhangs. No significant difference in damage between fenced plots with 12.5- and 25-cm overhangs occurred, and no significant difference in mortality of radishes occurred between any of the treatments (Table 1).

Table 1. Mean percentage of total radishes dead, and surviving radishes damaged by $D$. radicum feeding, in unfenced radish plantings and in radish plantings enclosed by fences with varying overhang lengths

\begin{tabular}{|c|c|c|c|c|c|c|}
\hline \multirow[b]{2}{*}{ Treatment } & \multicolumn{3}{|c|}{$\%$ dead } & \multicolumn{3}{|c|}{$\%$ damaged } \\
\hline & $\begin{array}{c}\text { Trial } 1 \\
13 / 07- \\
10 / 08 / 94\end{array}$ & $\begin{array}{c}\text { Trial } 2 \\
12 / 08- \\
30 / 08 / 94\end{array}$ & $\begin{array}{c}\text { Trial } 3 \\
23 / 08- \\
14 / 09 / 95\end{array}$ & $\begin{array}{c}\text { Trial } 1 \\
13 / 07- \\
10 / 08 / 94\end{array}$ & $\begin{array}{c}\text { Trial } 2 \\
12 / 08- \\
30 / 08 / 94\end{array}$ & $\begin{array}{c}\text { Trial } 3 \\
23 / 08- \\
14 / 09 / 95\end{array}$ \\
\hline No fence & $10.4 \mathrm{a}$ & $6.1 \mathrm{a}$ & $50.4 \mathrm{a}$ & $61.0 \mathrm{a}$ & $68.1 \mathrm{a}$ & $84.0 \mathrm{a}$ \\
\hline Fence without overhang & $2.4 \mathrm{~b}$ & - & - & $40.6 \mathrm{ab}$ & - & - \\
\hline Fence with 12.5 -cm overhang & - & $1.4 \mathrm{a}$ & - & - & $28.0 \mathrm{~b}$ & - \\
\hline Fence with $25-\mathrm{cm}$ overhang & $2.2 \mathrm{~b}$ & $0.2 \mathrm{a}$ & $6.0 \mathrm{~b}$ & $22.0 \mathrm{~b}$ & $25.7 \mathrm{~b}$ & $33.3 \mathrm{~b}$ \\
\hline Fence with $50-\mathrm{cm}$ overhang & - & - & $2.2 \mathrm{~b}$ & - & - & $15.8 \mathrm{c}$ \\
\hline
\end{tabular}

Means with different letter within a column are significantly different at $\alpha=0.05$. 
Table 2. Percent reduction in female $D$. radicum catch, and radish damage, inside enclosures with varying overhang lengths, relative to corresponding control plots

\begin{tabular}{|c|c|c|c|c|c|c|}
\hline \multirow[b]{2}{*}{ Treatment } & \multicolumn{3}{|c|}{$\%$ D. radicum catch reduction } & \multicolumn{3}{|c|}{$\%$ damage reduction } \\
\hline & $\begin{array}{c}\text { Trial } 1 \\
13 / 07- \\
10 / 08 / 94\end{array}$ & $\begin{array}{c}\text { Trial } 2 \\
12 / 08- \\
30 / 08 / 94\end{array}$ & $\begin{array}{c}\text { Trial } 3 \\
23 / 08- \\
14 / 09 / 95\end{array}$ & $\begin{array}{c}\text { Trial } 1 \\
13 / 07- \\
10 / 08 / 94\end{array}$ & $\begin{array}{c}\text { Trial } 2 \\
12 / 08- \\
30 / 08 / 94\end{array}$ & $\begin{array}{c}\text { Trial } 3 \\
23 / 08- \\
14 / 09 / 95\end{array}$ \\
\hline Fence without overhang & 61 & - & - & 35 & - & - \\
\hline Fence with 12.5 -cm overhang & - & 67 & - & - & 59 & - \\
\hline Fence with $25-\mathrm{cm}$ overhang & 84 & 87 & 84 & 64 & 63 & 59 \\
\hline Fence with $50-\mathrm{cm}$ overhang & - & - & 94 & - & - & 81 \\
\hline
\end{tabular}

Damage reduction is the percent reduction in the proportion of total radishes dead or damaged.

In the third trial, significant differences in the proportion of radishes damaged was observed between all treatments. Significantly more radishes died in the control plots than in the two fenced treatments (Table $1)$.

\section{Discussion}

The data show that collection overhangs can increase the effectiveness of exclusion fences. During the final three trapping sessions of the first trial, the number of female D. radicum captured inside fenced enclosures without overhangs was higher than the number caught inside fences with standard $25-\mathrm{cm}$ overhangs (Fig. 2). Damage to surviving radishes inside fences without overhangs was not significantly different from damage in the open control plots (Table 1). In contrast, radishes inside fences with overhangs suffered less damage than those in open control plots (Table 1).

The percentage reductions in female $D$. radicum catches inside fenced enclosures, relative to control plots in each trial, are shown in Table 2. In each trial the greatest reduction was observed in the treatment with the longest overhang. Reductions afforded by fences with standard $25-\mathrm{cm}$ overhangs are consistent between the three trials (range, $84-87 \%$ ). This result is comparable to the observation by Vernon and Mackenzie (1998) that $90 \mathrm{~cm}$ high exclusion fences with $22-\mathrm{cm}$ overhangs reduced female $D$. radicum catches by $\approx 82 \%$ compared with open controls over 2 yr of study.

Reductions in crop damage were not as large as reductions in female $D$. radicum catches, but tended to increase with overhang length (Table 2). Because $D$. radicum feeding could not always be confirmed as the cause of death in severely decomposed radishes, we chose to present the proportion of surviving radishes damaged by $D$. radicum feeding separately from the proportion of radishes dead at the time of inspection (Table 1). The omission of dead radishes in the calculation of damage reductions had little effect $( \pm 2 \%)$ on the damage reduction figure, therefore Table 2 shows percentage reductions in dead and damaged radishes together.

Although the number of $D$. radicum females caught per trapping day in the third trial was lower than in the first two, the percentage of radishes dead or damaged in control plots and standard fence enclosures was higher. This may be the result of the longer incubation period allowed between removal from the field and radish inspection in the third trial (25-30 d) than in the first two trials (8-12 d). Differences in trial length might also contribute to this effect, because the third trial was also the longest. Despite these differences, the damage reductions afforded by the standard fence with a $25-\mathrm{cm}$ overhang were similar in all three trials (Table 2), suggesting that some comparisons could be made between the trials.

It is important to note that the effective height of a fence decreases as overhang length increases. The effective height of an exclusion fence is the distance from the bottom of the overhang to the ground. In this study, fences with 0 -, 12.5-, 25-, and 50-cm overhangs all had a maximum height of $135 \mathrm{~cm}$, but their effective heights were actually $135,126,117$, and $100 \mathrm{~cm}$, respectively. Theoretically, the smaller the effective height, the less effective a fence will be in excluding D. radicum from an enclosure. Vernon and Mackenzie (1998) showed this to be true for fences under $90 \mathrm{~cm}$ high, but their work did not involve fences higher than $90 \mathrm{~cm}$. In this experiment, the increase in efficacy afforded by longer overhangs more than compensated for any loss caused by decreases in effective height. We cannot assume that this trend would continue if increasing overhang length further reduced effective height.

To achieve $>80 \%$ exclusion of female $D$. radicum, fences should have an effective height of at least $90 \mathrm{~cm}$, with an overhang of at least $25 \mathrm{~cm}$. The trends shown in our data and those of Vernon and Mackenzie (1998) suggest that efficacy of exclusion fences might be further improved with increases in effective fence height above $90 \mathrm{~cm}$ and overhang length $>50 \mathrm{~cm}$. Although these potentially superior permutations of effective fence height and overhang length were not tested in either study, it is likely that the additional costs of materials and the awkwardness of the resulting fence structures would impair their chances of being used by growers.

\section{Acknowledgments}

Thanks to Amanda Bates and Sherah van Laerhoven for help with fieldwork and root damage assessment. Thanks to Dave Raworth and Sheila Fitzpatrick for comments on the manuscript. This study was supported by grants from Energy, Mines and Resources (PERD program) (M.K.B. and R.S.V.), and by the Wenner-Gren Foundations, Sweden (P.P.). 


\section{References Cited}

Brooks, A. R. 1951. Identification of the root maggots (Diptera: Anthomyiidae) attacking cruciferous crops in Canada with notes on biology and control. Can. Entomol. 183: 109-120.

Finch, S. 1993. Integrated pest management of the cabbage root fly and the carrot fly. Crop Prot. 12: 423-430.

Haseli, A., and P. Conrad. 1987. An alternative for plant protection in vegetables: pest attack control with nets. Gemuse-Munchen 23: 320-324.

Hough-Goldstein, J. A. 1987. Tests of a spun polyester row cover as a barrier against seedcorn maggot (Diptera: Anthomyiidae) and cabbage pest infestations. J. Econ. Entomol. 80: 768-772.

Millar, K., and M. B. Isman. 1988. The effects of spunbonded polyester row covers on cauliflower yield loss caused by insects. Can. Entomol. 120: 45-47.
Schoene, W. J. 1914. The cabbage maggot in relation to the growing of early cabbage. Bulletin No. 382. New York Agricultural Experiment Station, Geneva.

Skinner, G., and S. Finch. 1986. Reduction of cabbage root fly (Delia radicum) damage by protective disks. Ann. Appl. Biol. 108: 1-10.

Vernon, R. S., and J. R. Mackenzie. 1998. The effect of exclusion fences on the colonization of rutabagas by cabbage flies (Diptera: Anthomyiidae). Can. Entomol. 130: 152-163.

Wheatley, G. A. 1975. Physical barriers for controlling cabbage root fly. National Vegetable Research Station Annual Report (Wellsbourne) for 1974. 97pp.

Zar, J. H. 1998. Biostatistical analysis, 4 th ed. Prentice-Hall, Upper Saddle River, NJ.

Received for publication 17 June 1998; accepted 2 March 2000. 